\title{
Building Welcoming Communities: Durham Libraries Engage Diversity
}

\author{
Durham Library Partners in Diversity (DLPD)
}

Keywords: diversity; Durham (Ontario, Canada); collaborative; coordination; positive space; welcoming communities

Publication Type: poster

\begin{abstract}
Public libraries are one of the last free shared spaces in a community. At their best, public libraries provide a positive space for diverse communities to come together, learn, share, and shape their communities. They play a critical, though sometimes overlooked, role in the settlement and integration of newcomers.

Public library staff in Durham Region have joined together to create welcoming communities for diverse populations across the Region. Through representation on the Local Diversity and Immigration Partnership Council, membership with the Welcome Centre Immigrant Services sites, engagement in Public Health priority neighbourhood strategic initiatives, shared programming, joint positive space and cultural competency training for all library staff, and a myriad of other joint program initiatives, public libraries in Durham are intentionally engaging, supporting, and learning from the diverse populations that make up the Region (and beyond!).
\end{abstract}

With a population of 645,000 , Durham Region lies to the east of the City of Toronto and is part of the Greater Toronto Area (GTA). The Region is growing in both population numbers and in diversity. It is made up of eight municipalities and each of those municipalities has a public library system. In 2009, representatives from the eight Durham libraries came together to better coordinate multilingual library collections across the Region. The scope of the group quickly expanded to include multicultural joint programming initiatives and training. It morphed again in 2015 to include “big-D" Diversity, a greater involvement in policy development and an expanded focus on all-staff training opportunities. This change in scope is reflected in the name of the collaborative, Durham Library Partners in Diversity (DLPD).

This poster presentation provides details on the growth of the DLPD collaborative and highlights the joint programming and community-wide initiatives. It also shares the impacts the collaborative has had on member organizations as well as on the community at large.

Durham Library Partners in Diversity (DLPD) is a network of public library professionals from the eight municipal library systems in Durham Region, Ontario plus representation from the Local Immigration Partnership (LIP). The DLPD provides opportunities for members' professional development, and opportunities to collaborate on research or activities aimed 
at improving multicultural services to diverse populations in Durham Region libraries.

Note: Any inquiries regarding this poster should be directed to: Sabrina Yung, Chair of the DLPD, Manager of Community Engagement, Pickering Public Library, email: sabrinay@picnet.org. 